\title{
A Cognitive Perspective on the Coherent and Cohesive Functions of Conceptual Metaphor
}

\author{
Hui Shao \\ English College of Dalian University, Dalian, China \\ shaohui002@yeah.net
}

Keywords: Conceptual metaphor; Cohesion; Coherence; Discourse

\begin{abstract}
Metaphor has been studied from different perspectives. During recent years, with the development of cognitive linguistics, many studies in philosophy and linguistics on metaphor have shifted the focus of scientific inquiry from a strictly linguistic plane to a cognitive - based stance. Conceptual metaphor has been explored from various perspectives including the types, the nature, the experiential basis and its three basic functions. But few studies have focused the attention on its cohesive and coherent functions in discourse. This paper focuses on the cohesive and coherent functions of metaphor in discourse.
\end{abstract}

\section{Introduction}

Since the publication of the book Cohesion in English [1], cohesion and coherence have been two important topics in discourse analysis. But all the studies on cohesion just focus on the lexical and grammatical cohesive devices. Few studies concern that conceptual metaphor also can perform the cohesive and coherent functions. Metaphor in the cognitive linguistic view means conceptual metaphor. Conceptual metaphor has been explored from different perspectives including its functions. Paul Ricoeur [2] begins to study metaphor from the perspective of discourse analysis in his book The Rule of Metaphor [2]. However, they have not made detailed analysis of the textual function. The objective of this paper is to explore how conceptual metaphor plays the cohesive and coherent roles through some cohesive devices in discourse.

\section{Cohesion and Coherence in Discourse Analysis}

Cohesion in Discourse. Cohesion is an important concept in discourse analysis. Linguists provide different definitions of cohesion. Halliday [3] indicates that in order to construct discourse we need to be able to establish additional relations within the discourse that are not subject to these limitations. These relations cannot be achieved by grammatical structure; they depend on a resource of a rather different kind. These non-structural resources for discourse are what are referred to by the term cohesion. Halliday and Hasan [1] point out that cohesion occurs where the interpretation of some element in the discourse is dependent on that of another. The one presupposes the other, in the sense that it cannot be effectively decoded except by recourse to it. When this happens, a relation of cohesion is set up. According to their definition, the understanding of the presupposed elements should depend on the presupposing elements. And the presupposing and the presupposed elements are potentially integrated into a text. There are four ways by which cohesion is created in English: reference, ellipsis and substitution, conjunction, and lexical cohesion.

Coherence in Discourse. Coherence refers to the relationship which links two meanings of utterances in a discourse and these links may be based on the communicators' shared knowledge and context. Unlike cohesion, coherence is the underlying semantic relation. Consider the following example:

A. Pass me the pen, please.

B. I am reading a novel.

A. Ok, I know. (example 1)

In the above example, speaker A can understand what speaker B's answer means although 
speaker B does not directly accept or refuse A's request. This understanding is based on the context and this conversation is coherent. The whole conversation should be as the following:

A. Pass me the pen. I can't reach it.

B. No, I'm sorry I can't because I' $m$ busy reading a novel.
A. Ok, I will go to get it.
(example 2)

Both the above two conversations are coherent although there are no explicit cohesive devices. The coherence of example (1) is made from the context, without which, the interpretation of the conversation would be impossible. There are some conditions that can keep one discourse coherent, that is, the context of culture, cognitive model and the context of circumstance, etc.

\section{Conceptual Metaphor in Cognitive Linguistics}

The Definition of Conceptual Metaphor. Barcelona [4] defines metaphor as "the cognitive mechanism whereby one experiential domain is partially 'mapped', i.e. projected, onto a different experiential domain, so that the second domain is partially understood in terms of the first one. Kövecses [5] indicates that in the cognitive linguistic view, metaphors are sets of mappings between a more concrete or physical source domain and a more abstract target domain. And metaphor in the cognitive linguistic view means conceptual metaphor. Currently, metaphor has been studied from the cognitive perspective with the development of cognitive linguistics.

Sample Discourse Analysis. I would describe life in terms of a journey. But we're walking through it. Sometimes we see clearly and other times it's dark and hidden. And you can still walk and think through it. And walking through it, in walking through darkness, you come to a fuller understanding. A sense of it. And sometimes tripping and falling. And yet still "come follow me" is what you have to remember. Get up again and continue on the journey. [6]

The above passage is written by Dave who is a Catholic priest about life. There is a conceptual metaphor LIFE IS A JOURNEY that goes through the whole passage. Dave describes life as a journey. In this conceptual metaphor, the domain of JOURNEY is mapped onto the domain of LIFE. On a journey, there may be difficulties, that is to say, the journey may be clear or dark and hidden. If the traveler does not take a care he or she will trip on the journey. Then he or she should stand up again and go on with the journey. There are some mappings between the domain of LIFE and that of JOURNEY. There are many difficulties in one's life. And one has to be brave and keep on going when meeting some difficulties that are inevitable in his life. The whole passage is linked tightly by one conceptual metaphor LIFE IS A JOURNEY which belongs to structural metaphor. The following diagram shows how this conceptual metaphor develops the whole discourse:

From this figure, we can see that the conceptual metaphor LIFE IS A JOURNEY goes through the whole passage; develops the topic and links the passage into a unified discourse. Some verbs and phrases such as walk, come follow me and get up are originally used to describe journey. These JOURNEY words are used here to describe life. Some words such as clearly, dark, hidden, tripping and falling are also used to show the features of a journey, but they are used to describe life here. This diagram indicates that the conceptual metaphor LIFE IS A JOURNEY can expand the content of the whole discourse and develop the topic. Cohesive device repetition is used here with the repetition of the metaphorical verb walk. We usually use the phrase walk on the journey. But the word walk here is used to describe that we are living a life that is full of frustrations, which is just like walking through a long journey. 


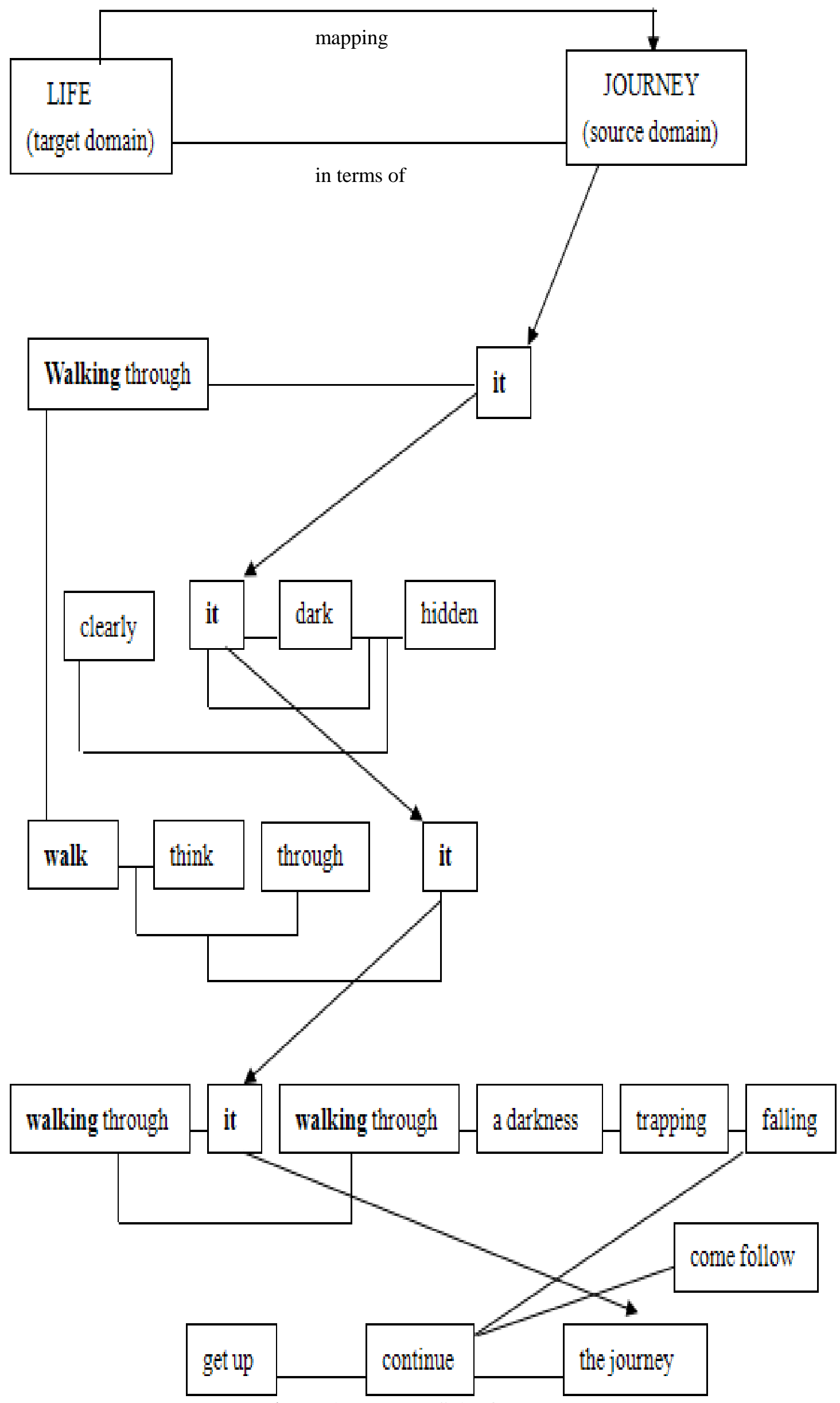

Figure 1. LIFE IS A JOURNEY 
In this discourse, the conceptual metaphor LIFE IS A JOURNEY uses cohesive devices such as repetition and reference (endophoric reference and exophoric reference) of the vehicle terms to maintain the cohesiveness of the discourse. The pronoun it refers to the word journey but in fact, it here refers to the word life with regard to the use of the conceptual metaphor LIFE IS A JOURNEY. For example, the third sentence Sometimes we see clearly and other times it's dark and hidden implicates that sometimes life is dark and hidden. Because of this, the pronoun it is a metaphorical pronoun here and is repeated throughout the whole discourse. Cohesion is not a guarantee of coherence but it can help to maintain coherence. So the cohesion created by the conceptual metaphor in this discourse can help to make the discourse coherent.

\section{Conclusions}

Cohesion and coherence are two important terms in discourse analysis. Many researches have been carried out on the four cohesive devices and the relationship between cohesion and coherence. However, most of the studies of cohesion in the past just focus on the lexical and grammatical level. This paper extends the studies of cohesion from the lexical and grammatical level to the cognitive linguistic level. That is to say, this study holds that conceptual metaphor can perform the cohesive and coherent functions in discourse.

It should be recognized that these functions of conceptual metaphor play a crucial role in teaching. That is to say, the use of metaphors in discourse makes the discourse more vivid but the understanding of the metaphors is not easy. Conceptual metaphors in the reading passages both contribute to and limit understanding. If we do not understand the conceptual metaphors in reading materials, we will have difficulty comprehending the whole reading passage. We usually meet some conceptual metaphors in reading materials. In these materials, conceptual metaphors can affect students' understanding of the materials. If students cannot understand the metaphors, they may misunderstand the whole passage. Metaphors have the potential for causing misunderstanding, especially when there are mismatches between a text writer's intentions behind a metaphor use and the worldly knowledge that students bring to their classroom learning environment. Because of the importance of conceptual metaphor, the teacher should try to cultivate students' metaphorical abilities. And the teacher's task is to train students' ability to analyze the conceptual metaphors in the reading material. conceptual metaphor plays an important role in the process of discourses and thus the understanding of conceptual metaphor is important for the teaching of reading.

\section{References}

[1] M. A. K. Halliday and R. Hasan. Cohesion in English. Foreign Language Teaching and Research Press, China, 1976/2001

[2] P. Ricoeur. The Rule of Metaphor. Routledge \& Kegan Paul, Britain, 1975/1986.

[3] M. A. K. Halliday. An Introduction to Functional Grammar (2nd eds.). Foreign Language Teaching and Research Press, China, 2000.

[4] A. Barcelona, The cognitive theory of metaphor and metonymy. In A. Barcelona (ed.). Metaphor and Metonymy at the Crossroads. Mouton de Gruyer, Germany and US, 2003.

[5] Z. Kövecses. Metaphor: A Practical Introduction. Oxford University Press, US, 2002.

[6] D. F. Shu. Study on Metaphor. Shanghai Foreign Language Education Press, China, 1999. 